\title{
Occupational Exposures and Gastrointestinal Cancers Among Finnish Women
}

\section{Elisabete Weiderpass, MD, PhD \\ Harri Vainio, MD, PhD \\ Timo Kauppinen, PhD \\ Kaisa Vasama-Neuvonen, MSc \\ Timo Partanen, PhD \\ Eero Pukkala, PhD}

A cohort including all female workers born 1906 through $1945(\mathrm{n}=$ 413,877) in Finland was identified through the Population Census of Finland of 1970. Incident cases of cancers of the gastrointestinal tract were explored during 1971 to 1995. Job titles in census records were converted to exposures of 31 occupational agents through a jobexposure matrix. For each agent, the product of level and probability of exposures was calculated and subdivided in three categories: zero, low and medium/high. Poisson regression models estimated relative risks (RR) for each agent, standardized for birth cohort, follow-up period, and socioeconomic status. Adjustment at job title level was done for alcohol use for cancers of the esophagus and liver and smoking for pancreatic cancer. The results showing either statistically significant $R R$ at the medium/high level of exposure $\left(R R_{H}\right)$ or statistically significant trend $(\mathrm{P}<0.05)$ over the exposure categories were considered as positive findings. Colon cancer risk (2009 cases) was positively associated with sedentary work $\left(R R_{H} 1.3,95 \% C I=1.1-1.6 ; \mathrm{P}\right.$ trend 0.001) and negatively associated with perceived workload ( $\mathrm{P}$ trend $=0.007)$. For stomach cancer $(1881$ cases), we observed an association with exposure to electromagnetic fields $\left(R R_{H} 1.44,95 \% C I=\right.$ 1.01-2.05) and man-made vitreous fibers (MMVF) ( $p$ trend 0.03). Rectal cancer (1323 cases) showed an association with chromium $\left(R R_{H} 1.9,95 \% C I=1.2-3.1\right)$ and oil mist (RR 2.0; $95 \% C I=1.0-3.9)$. For pancreas cancer (1302 cases) we found associations with exposure to chromium $\left(R R_{H} 1.8 ; 95 \% C I=1.0-3.1 ; \mathrm{P}\right.$ trend 0.01$)$, electromagnetic fields $\left(R R_{H} 1.8 ; 95 \% C I=1.2-2.8 ; \mathrm{P}\right.$ trend 0.02$)$, and sedentary work $\left(R R_{H} 1.3 ; 95 \%\right.$ $C I=1.0-1.7 ; \mathrm{P}$ trend 0.05$)$. We found no significant associations between any FINJEM agents and cancers of the esophagus (389 cases), liver (389 cases), and gallbladder (651 cases). Having examined the associations between seven cancer sites and over 30 exposures there exists the real possibility that some of the associations detected are chance findings. Therefore, the associations observed should need to be confirmed in other studies. (J Occup Environ Med. 2003;45:305-315)

From the International Agency for Research on Cancer, Lyon, France (Dr Weiderpass, Dr Vainio); Department of Medical Epidemiology, Karolinska Institutet, Stockholm, Sweden (Dr Weiderpass); Department of Epidemiology and Biostatistics, Finnish Institute of Occupational Health, Helsinki, Finland (Dr Vainio, Dr Vasama-Neuvonen, Dr Partanen); School of Public Health, University of Tampere, Tampere, Finland (Dr Vasama-Neuvonen, Dr Partanen); Central American Institute for Studies on Toxic Substances, Universidad Nacional, Heredia, Costa Rica (Dr Partanen); and the Finnish Cancer Registry, Institute for Statistical and Epidemiological Cancer Research, Helsinki, Finland (Dr Pukkala).

This study was supported by the Finnish Work Environment Fund and the Foundation for the Finnish Cancer Institute.

Address correspondence to: Elisabete Weiderpass, MD, PhD, International Agency for Research on Cancer, Unit of Field and Intervention Studies, 150 cours Albert Thomas, F-69372 Lyon Cedex 8 France; e-mail: Weiderpass@iarc.fr.

Copyright ( $)$ by American College of Occupational and Environmental Medicine

DOI: 10.1097/01.jom.0000052963.43131.44 ccupational factors for gastrointestinal cancers, including cancers of the liver, gallbladder, and pancreas, are not well established. For various occupational chemical and physical exposures, a large Canadian casecontrol study has produced a number of associations; ${ }^{1}$ however, other supporting evidence for many of these associations observed is meagre., ${ }^{2,3}$ Several epidemiological studies have shown inverse association between job activity and colon cancer risk. ${ }^{4}$ Some occupational exposures, such as exposure to some organic dusts, iron oxides, polyurethanes, waxes and polishes, and toluene have been reported to increase the risk of colon cancer in the Canadian case-control study. ${ }^{1}$

In the same case-control study, a considerable number of occupational agents was associated with increased risk of rectal cancer, among them substantial exposure to various solvents, biocides, cleaning agents, diesel oil, engine emissions, glass fibers, a number of organic dusts, and synthetic fibers. ${ }^{1}$

Aflatoxins, vinyl chloride, and hepatitis B and C infections (occupational and non-occupational) increase risk of liver cancer. Trichloroethylene and polychlorinated biphenyls (PCBs) may do so. ${ }^{3}$ In the Canadian case-control study, substantial exposures to abrasives dust, aluminum, calcium oxide, various organic dusts were associated with increased gallbladder cancer incidence. $^{1}$

Tobacco smoking increases the risk of pancreatic cancer. The association between environmental tobacco smoke 
TABLE 1

Primary Sites, ICD-7 Codes, Incidence and Numbers of Cases in the Study

\begin{tabular}{llrr} 
Primary site & ICD-7 & Incidence per $\mathbf{1 0 0 , 0 0 0 ~ ( 1 9 9 5 )}$ & Number of cases \\
\hline Esophagus & 150 & 1.5 & 389 \\
Stomach & 151 & 7.1 & 1,881 \\
Colon & 153 & 12.2 & 2,009 \\
Rectum & 154 & 6.8 & 1,323 \\
Liver & 155.0 & 1.4 & 389 \\
Gallbladder & 155.1 & 2.9 & 651 \\
Pancreas & 157 & 5.7 & 1,302 \\
\hline
\end{tabular}

Employed Finnish women 1971, Social Classes 3 and 4. Social classes 1 and 2 and farmers were excluded.

\section{TABLE 2}

FINJEM Estimates for the Proportion of Exposed among Employed, mean Exposure Levels in 1960-1984 among those Exposed, Cutpoints between Low and High Exposure Levels for the Occupational Agents of the Present Study in Finland (Men and Women Pooled), and the International Agency for Research on Cancer (IARC) Classification of Carcinogenicity ${ }^{\mathrm{a}}$ to Humans.

\begin{tabular}{|c|c|c|c|c|c|c|}
\hline Agent & $\begin{array}{l}\text { Estimated } \\
n \text { exposed } \\
\text { (thousands) }\end{array}$ & $\begin{array}{c}\text { \% Ex- } \\
\text { posed } \\
\text { among } \\
\text { employed }\end{array}$ & Unit & $\begin{array}{c}\text { Exposure } \\
\text { level } \\
\text { Mean }\end{array}$ & $\begin{array}{l}\text { Cutpoint be- } \\
\text { tween low } \\
\text { and high } \\
\text { exposure } \\
\text { levels }\end{array}$ & $\begin{array}{c}\text { IARC } \\
\text { Classification } \\
\text { for carcino- } \\
\text { genicity }^{\mathbf{a}}\end{array}$ \\
\hline Aliphatic/alicyclic hydrocarbon solvents & 28 & 1.3 & $\mathrm{ppm}$ & 20.0 & 6.5 & $2 \mathrm{~A}-2 \mathrm{~B}, 3$ \\
\hline Animal dust & 250 & 12 & $\mathrm{mg} / \mathrm{m}^{3}$ & 0.05 & 0.01 & - \\
\hline Aromatic hydrocarbon solvents & 20 & 1.0 & $\mathrm{ppm}$ & 15.0 & 1.0 & $1-3$ \\
\hline Cadmium & 10 & 0.5 & $\mu \mathrm{g} / \mathrm{m}^{3}$ & 0.9 & 0.23 & 1 \\
\hline Chlorinated hydrocarbon solvents & 8 & 0.4 & ppm & 8.0 & 0.2 & $2 \mathrm{~A}-2 \mathrm{~B}, 3$ \\
\hline Chromium & 51 & 2 & $\mu \mathrm{g} / \mathrm{m}^{3}$ & 12 & 1.0 & $1-3$ \\
\hline Diesel engine exhaust & 48 & 2 & $\mathrm{mg} / \mathrm{m}^{3}$ nitrogen dioxide & 0.6 & 0.4 & $2 \mathrm{~A}$ \\
\hline Flour dust & 13 & 0.6 & $\mathrm{mg} / \mathrm{m}^{3}$ & 4.0 & 0.8 & - \\
\hline Formaldehyde & 50 & 2 & $\mathrm{Ppm}$ & 0.2 & 0.03 & $2 \mathrm{~A}$ \\
\hline Iron & 132 & 6 & $\mathrm{mg} / \mathrm{m}^{3}$ & 0.2 & 0.5 & - \\
\hline Lead & 57 & 3 & $\mu \mathrm{mol} / \mathrm{l}$ & 0.9 & 0.3 & $2 \mathrm{~B}$ \\
\hline Low frequency electromagnetic fields & 424 & 20 & $\mu \mathrm{T} / 24 \mathrm{~h}$ & 0.4 & 0.8 & - \\
\hline Man-made vitreous fibers & 62 & 3 & fibers $/ \mathrm{cm}^{3}$ & 0.2 & 0.02 & 2B \\
\hline Nickel & 44 & 2 & $\mu \mathrm{g} / \mathrm{m}^{3}$ & 8.0 & 6.7 & $1-2 B$ \\
\hline Oil mist & 34 & 1.6 & $\mathrm{mg} / \mathrm{m}^{3}$ & 1.5 & 0.7 & $1-2 A, 3$ \\
\hline Other mineral dusts & 94 & 5 & $\mathrm{mg} / \mathrm{m}^{3}$ & 1.3 & 3.0 & $1-3$ \\
\hline Perceived physical work load & 846 & 40 & score $0-2$ & 0.6 & 0.2 & - \\
\hline Polycyclic aromatic hydrocarbons & 71 & 3 & $\mu \mathrm{g} / \mathrm{m}^{3}$ & 1.0 & 5.0 & $1-2 A, 3$ \\
\hline Sedentary work & 173 & 8 & score $0-2$ & 0.7 & 0.4 & - \\
\hline Silica dust & 108 & 5 & $\mathrm{mg} / \mathrm{m}^{3}$ & 0.1 & 0.1 & 1 \\
\hline Textile dust & 49 & 2 & $\mathrm{mg} / \mathrm{m}^{3}$ & 0.6 & 0.4 & - \\
\hline
\end{tabular}

\footnotetext{
${ }^{a}$ Group 1: Carcinogenic to humans; 2A: Probably carcinogenic to humans; 2B: Possibly carcinogenic to humans; 3: Unclassifiable.
}

b 2.12 million, both genders (1960-84). FINJEM does not differentiate between men and women.

${ }^{\circ}$ Occupational exposure to heat from natural of artificial sources exceeding continuously $28^{\circ} \mathrm{C}$ or higher (due to strong thermal radiation, heavy clothing, high activity levels). The unit of measurement is "\% of the time in heat" and the cutpoint between low and high has been defined by the proportion of exposed workers, and set at $5 \%$.

and pancreatic cancer is less clear. Exposure to aliphatic and alicyclic hydrocarbons, chlorinated hydrocarbon solvents, polycyclic aromatic hydrocarbons, and silica dust may increase risk of pancreatic cancer. ${ }^{5-8}$
As part of a national populationbased incidence study on cancer risk among Finnish women, this report 
TABLE 3

Esophagus Cancer. Relative Risk for Low $\left(R R_{L}\right)$, and Medium/High $\left(R_{H}\right)$ Levels of Exposure to FINJEM Agents, with 95\% Confidence Intervals $(\mathrm{Cl})$

\begin{tabular}{|c|c|c|c|c|c|}
\hline Agent & $\mathbf{R R}_{\mathbf{L}}$ & $95 \% \mathrm{Cl}$ & $\mathbf{R R}_{\mathbf{H}}$ & $95 \% \mathrm{Cl}$ & $\mathbf{P}$ trend \\
\hline \multicolumn{6}{|l|}{ Physical agents } \\
\hline Heat & 0.98 & $0.76-1.27$ & - & - & 0.79 \\
\hline Ultraviolet radiation & 1.06 & $0.78-1.45$ & 0.90 & $0.49-1.67$ & 1.00 \\
\hline \multicolumn{6}{|l|}{ Chemical agents } \\
\hline Formaldehyde & 1.02 & $0.79-1.31$ & 0.94 & $0.54-1.65$ & 0.98 \\
\hline \multicolumn{6}{|l|}{ Organic solvents } \\
\hline Chlorinated hydrocarbons & 1.29 & $0.78-2.15$ & 0.90 & $0.54-1.49$ & 0.98 \\
\hline \multicolumn{6}{|l|}{ Organic dusts } \\
\hline Animal dust & 1.20 & $0.76-1.91$ & 0.59 & $0.08-4.32$ & 0.70 \\
\hline Flour dust & 0.99 & $0.78-1.27$ & 1.04 & $0.53-2.03$ & 1.00 \\
\hline Textile dust & 1.41 & $0.98-2.03$ & 1.27 & $0.88-1.84$ & 0.07 \\
\hline Wood dust & 0.99 & $0.77-1.28$ & 0.53 & $0.22-1.29$ & 0.38 \\
\hline Asbestos & 0.58 & $0.22-1.56$ & 1.16 & $0.47-2.83$ & 0.77 \\
\hline Man-made vitreous fibers & 1.29 & $0.83-2.00$ & 1.61 & $0.80-3.25$ & 0.09 \\
\hline Silica dust & 0.97 & $0.76-1.25$ & 1.57 & $0.85-2.91$ & 0.51 \\
\hline Other mineral dusts & 1.02 & $0.80-1.29$ & 1.60 & $0.51-5.06$ & 0.70 \\
\hline \multicolumn{6}{|l|}{ Metals } \\
\hline Cadmium & 0.92 & $0.38-2.22$ & 0.91 & $0.29-2.88$ & 0.81 \\
\hline Chromium & 0.66 & $0.36-1.21$ & 1.38 & $0.44-4.29$ & 0.48 \\
\hline Iron & 0.71 & $0.25-1.98$ & 1.54 & $0.22-11.0$ & 0.78 \\
\hline Lead & 1.12 & $0.72-1.76$ & 0.68 & $0.22-2.15$ & 0.92 \\
\hline Nickel & 0.75 & $0.33-1.74$ & 1.15 & $0.16-8.29$ & 0.64 \\
\hline Arsenic & 0.58 & $0.22-1.56$ & 1.16 & $0.47-2.83$ & 0.77 \\
\hline \multicolumn{6}{|l|}{ Engine exhaust } \\
\hline
\end{tabular}

- not estimated (small data)

Reference category: no exposure. Adjusted for alcohol consumption and turnover rate.

discusses associations between selected chemical and physical occupational agents and the incidence of seven different gastrointestinal tract-linked cancer sites in Finnish women in blue-collar occupations. The study is based on a linkage model of occupational census data, cancer incidence data and an intervening job-exposure matrix. Cancer incidence and exposures were assessed at the job title level, not individually.

\section{Materials and Methods}

The structure of the Women's Occupational Cancer Study in Finland has been described in detail elsewhere. $^{9}$ Out of a cohort of 892,591 women born in 1906 through 1945 and reporting having an occupation at the Population Census of Finland 1970, we excluded from the analysis managers and other high administrative or clerical employees, lower administrative or clerical employees, small-scale entrepreneurs and farmers. The exclusion was done because of lifestyle differences and the scarcity of industrial chemical exposures, compared to the remaining subcohort of 413,877 women workers in the industry and service sectors, consisting of 183 job titles. ${ }^{10}$ The subcohort was followed up for cancer incidence from January 1, 1971 through emigration, death, or common closing date (December 31, 1995), whichever occurred first, through a computerized record linkage with the Finnish Cancer Registry files. The linkage was based on the unique personal identifier given to every resident of Finland and used as an identifier in both the Census and Cancer register files. The observed numbers of cancer cases are given in Table 1.

A special feature of this study was the use of a national job exposure matrix. The FINJEM Exposure In- 
TABLE 4

Stomach Cancer. Relative Risk for Low $\left(\mathrm{RR}_{\mathrm{L}}\right)$ and Medium/High $\left(\mathrm{RR}_{\mathrm{H}}\right)$ Levels of Exposure to FINJEM Agents, with $95 \%$ Confidence Intervals $(\mathrm{Cl})$

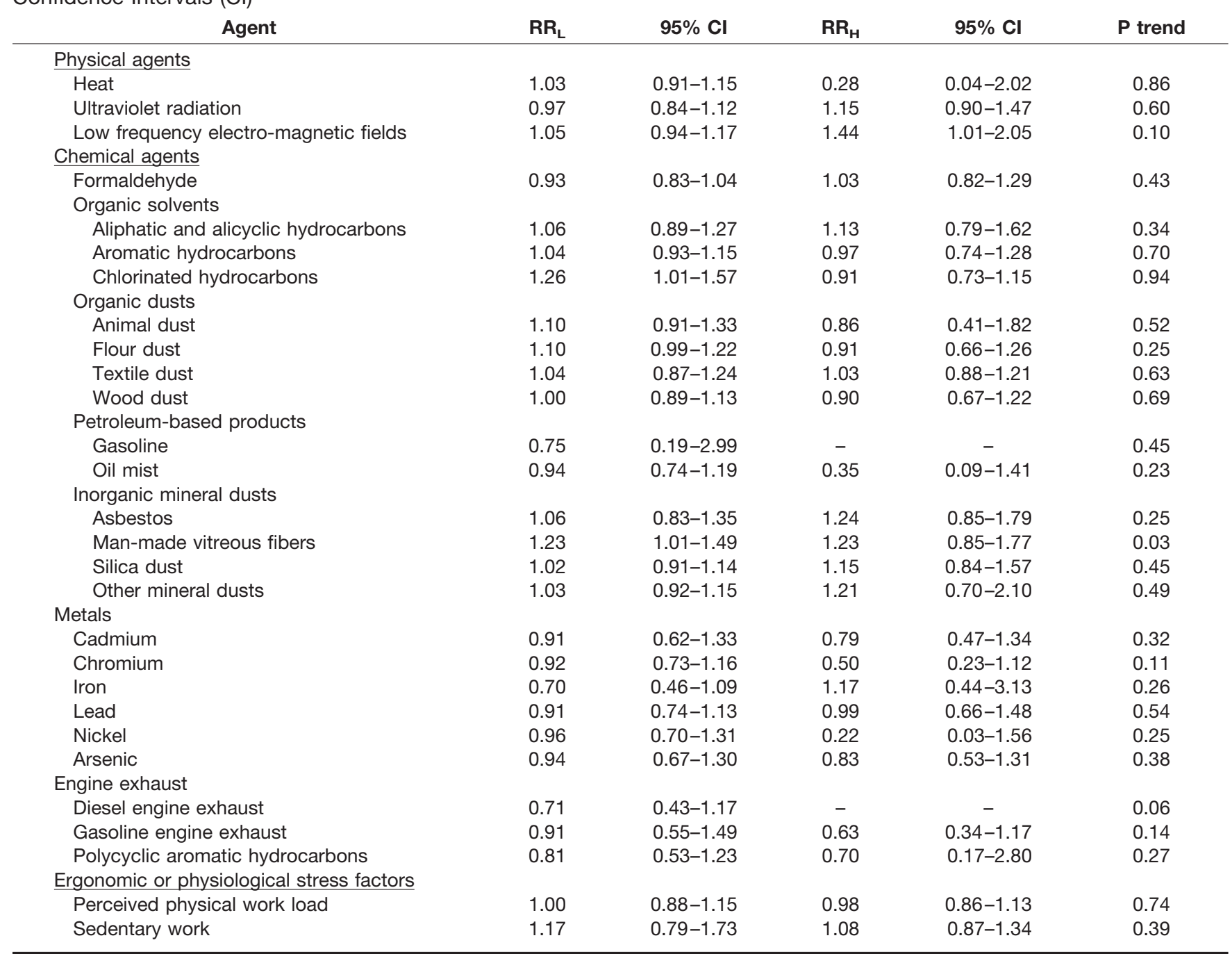

- not estimated (small data).

Reference category: no exposure. Adjusted for Turnover rate.

formation System ${ }^{11}$ includes occupation-specific estimates of prevalence and levels of exposure to major chemical, physical, microbiological, ergonomic, and psychosocial factors in Finland. FINJEM has three dimensions: occupations $(n=311)$, agents $(n=74)$, and exposure periods $(n=$ 4). Exposure to an agent in an occupation during a period is characterized with respect to the prevalence of exposure (proportion exposed) and average level of exposure (in ppm, $\mathrm{dB}$, score, or other unit of intensity). FINJEM was designed by a team of scientists experienced in assessing physical, chemical, ergonomic, and psychosocial exposures, making use of Finnish industrial hygiene measurements, interview surveys and workforce surveys.

For this study, the job titles were converted into probabilities (estimated proportions of exposed) and into mean levels of exposure among exposed for 28 selected chemical and physical agents, and 2 ergonomic agents with reference to the period 1960 through 1984 (Table 2). The agents were selected as representing the most prevalent occupational potential carcinogens in the Nordic countries.
For each FINJEM agent, the product of level and probability of an exposure was calculated, and subdivided into three categories: zero (reference category in the Poisson regression analysis described below); low (roughly below median among job titles with exposure probability $>0$ ); and medium/high (equal or above median).

Each job title was associated with observed and expected numbers of gastrointestinal cancers based on national rates of all economically active women. The expected numbers were stratified by 5-year birth cohort, 
TABLE 5

Colon Cancer. Relative Risk for Low $\left(R_{L}\right)$ and Medium/High $\left(R_{H}\right)$ Levels of Exposure to FINJEM Agents, with $95 \%$ Confidence Intervals (Cl)

\begin{tabular}{|c|c|c|c|c|c|}
\hline Agent & $\mathbf{R R}_{\mathbf{L}}$ & $95 \% \mathrm{Cl}$ & $\mathbf{R R}_{\mathbf{H}}$ & $95 \% \mathrm{Cl}$ & $\mathbf{P}$ trend \\
\hline \multicolumn{6}{|l|}{ Physical agents } \\
\hline Heat & 0.94 & $0.84-1.05$ & 1.00 & $0.37-2.65$ & 0.28 \\
\hline Ultraviolet radiation & 0.96 & $0.84-1.11$ & 0.98 & $0.76-1.27$ & 0.67 \\
\hline \multicolumn{6}{|l|}{ Chemical agents } \\
\hline Formaldehyde & 1.10 & $1.00-1.22$ & 0.93 & $0.74-1.17$ & 0.35 \\
\hline Organic solvents & 1.05 & $0.88-1.25$ & 1.23 & $0.89-1.70$ & 0.21 \\
\hline Chlorinated hydrocarbons & 1.21 & $1.01-1.44$ & 0.99 & $0.51-1.91$ & 0.07 \\
\hline \multicolumn{6}{|l|}{ Organic dusts } \\
\hline Animal dust & 0.93 & $0.84-1.04$ & 0.93 & $0.70-1.25$ & 0.21 \\
\hline Flour dust & 1.05 & $0.88-1.25$ & 1.13 & $0.98-1.31$ & 0.09 \\
\hline Textile dust & 0.91 & $0.81-1.03$ & 0.87 & $0.66-1.16$ & 0.09 \\
\hline Wood dust & 1.29 & $0.48-3.44$ & 3.53 & $0.88-14.1$ & 0.11 \\
\hline Asbestos & 1.14 & $0.95-1.38$ & 0.87 & $0.56-1.34$ & 0.60 \\
\hline Man-made vitreous fibers & 0.94 & $0.83-1.05$ & 0.87 & $0.61-1.23$ & 0.18 \\
\hline Silica dust & 0.93 & $0.83-1.05$ & 0.82 & $0.44-1.52$ & 0.20 \\
\hline Other mineral dusts & 0.97 & $0.68-1.38$ & 0.96 & $0.61-1.52$ & 0.82 \\
\hline \multicolumn{6}{|l|}{ Metals } \\
\hline Cadmium & 0.95 & $0.77-1.17$ & 0.59 & $0.29-1.18$ & 0.20 \\
\hline Chromium & 1.22 & $0.89-1.68$ & 0.26 & $0.04-1.84$ & 0.86 \\
\hline Iron & 1.07 & $0.88-1.30$ & 1.10 & $0.76-1.59$ & 0.40 \\
\hline Lead & 1.21 & $0.92-1.59$ & 0.39 & $0.10-1.56$ & 0.70 \\
\hline Nickel & 0.94 & $0.69-1.28$ & 0.61 & $0.37-1.01$ & 0.06 \\
\hline Arsenic & 1.19 & $0.80-1.77$ & 1.36 & $0.44-4.23$ & 0.31 \\
\hline \multicolumn{6}{|l|}{ Engine exhaust } \\
\hline
\end{tabular}

-not estimated (small data)

Reference category: no exposure. Adjusted for turnover rate.

5-year follow-up period, and social class. Poisson regression models ${ }^{12}$ were fitted to the data with the number of observed cases as the response variable, and the number of expected cases as the offset. The regression coefficients were interpreted as the $\log$ of the observed to expected ratios, exponentiation of which yields estimates of rate ratio (RR). The following known etiological factors were added into the Poisson regression models: alcohol use for cancers of the esophagus and liver, and smoking for pancreatic cancer. Information on these factors was available for each job title - not at the individual level. Turnover rate, defined as the proportion of subjects staying within a job title between 1970$1975,{ }^{13}$ was included in all models to diminish exposure misclassification bias due to use of cross-sectional job title as a surrogate of the unknown longest-held job.

The RRs for low and medium/ high exposure categories in the following text are marked with $\mathrm{RR}_{\mathrm{L}}$ and $\mathrm{RR}_{\mathrm{H}}$, respectively. A significance test of the regression coefficient over the exposure categories, scored $0,1,2$, was used as the test for trend. The association was considered 'significant' if the $95 \%$ confidence interval $(\mathrm{CI})$ of $\mathrm{RR}_{\mathrm{H}}$ does not include 1.0 or if the $P$ value for trend is $<0.05$.

\section{Results}

\section{Esophagus (Table 3)}

No significant associations were found between esophageal cancer and any of the exposures considered. For asbestos the RR was 1.16 (95\% CI $=0.47-2.83 ; P$ trend $0.77)$; for silica dust 1.57 (0.85$2.91 ; P$ trend 0.51$)$; and for 
TABLE 6

Rectal Cancer. Relative Risk for Low $\left(R_{L}\right)$ and Medium/High $\left(R_{H}\right)$ Levels of Exposure to FINJEM Agents, with $95 \%$ Confidence Intervals $(\mathrm{Cl})$

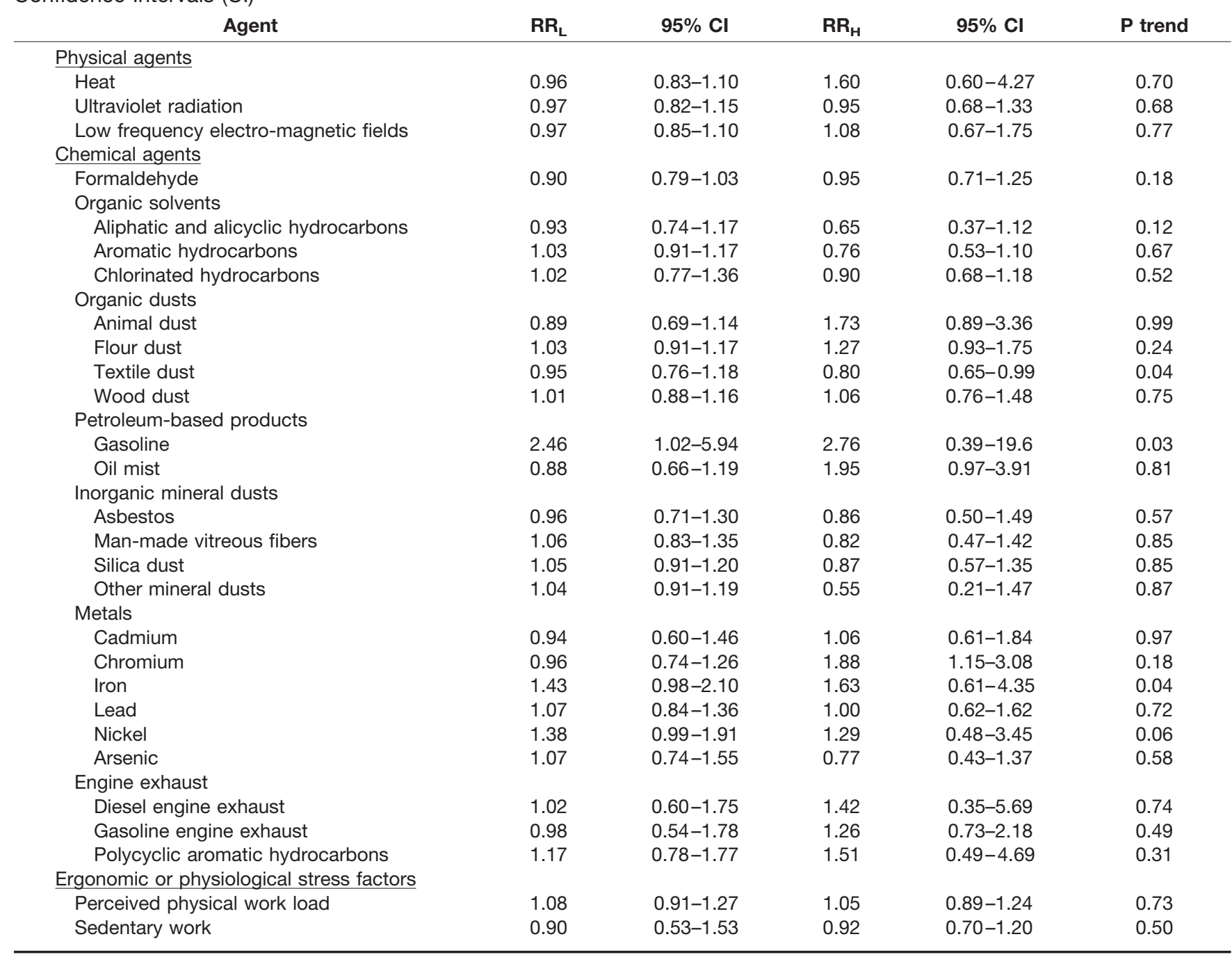

- not estimated (small data).

Reference category: no exposure. Adjusted for turnover rate.

MMVF, $1.61(0.80-3.25 ;$ P P P Colon (Table 5) trend 0.09).

\section{Stomach (Table 4)}

The RR high for electromagnetic fields was significantly elevated $(1.4495 \%$ CI $=1.01-2.05 ; P$ trend $=0.1$. A significant trend $(P=0.03)$ was observed for MMVF, although the magnitude of the association was similar for those with low and medium/high exposures. The RR for low level of exposure to chlorinated hydrocarbon solvents was significantly elevated, but there was a deficit in mortality at the medium/high level.
Sedentary work was associated with increased risk. $\mathrm{RR}_{\mathrm{L}}$ was 1.38 $(95 \% \mathrm{CI}=0.89-1.93)$ and $\mathrm{RR}_{\mathrm{H}} 1.32$ (1.10-1.59; $P$ trend 0.001). Perceived workload was inversely associated with risk $(P$ trend $=0.007)$. The RRs for animal dust (1.21) and formaldehyde (1.10) were significantly elevated for low level of exposure only.

\section{Rectum (Table 6)}

The RR for medium/high level of exposure to chromium was 1.88 $(95 \% \mathrm{CI}=1.15-3.08)(P$ trend
$0.18)$. Gradients of increasing risk with increasing exposure to iron $(P$ trend 0.04$)$. and gasoline fumes $(P$ trend 0.03 ) were found. There was a suggestive finding for oil mist exposure (RR for medium/high level 1.95; 0.97-3.91). The SIR for low level of exposure to ionizing radiation was 2.30 (1.03-5.12), while no cases were observed in medium/high level.

\section{Liver (Table 7)}

No significant associations were found, but the RR estimates for medium/high level of exposure to heat, 
TABLE 7

Liver Cancer. Relative Risk for Low $\left(R_{L}\right)$ and Medium/High $\left(R_{H}\right)$ Levels of Exposure to FINJEM Agents, with 95\% Confidence Intervals (Cl)

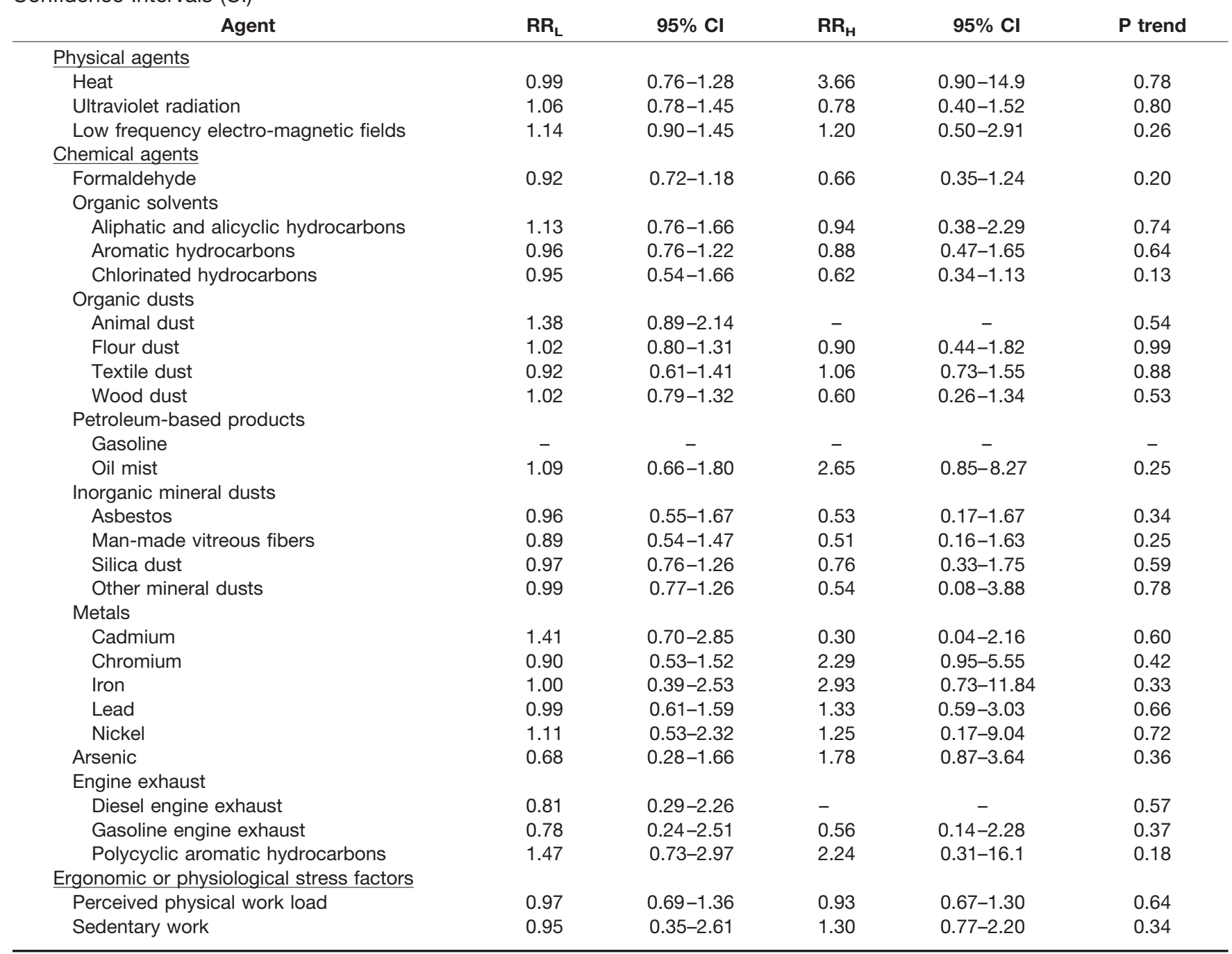

- not estimated (small data).

Reference category: no exposure. Adjusted for alcohol consumption and turnover rate.

chromium, iron, PAHs, and oil mist were elevated (2.29-3.66).

\section{Gallbladder (Table 8)}

No significant associations were found. The only elevated RR (6.00) was the one associated with medium/ high level of exposure to gasoline fume $(95 \% \mathrm{CI}=0.84-42.7)$.

\section{Pancreas (Table 9)}

The risk was significantly associated with medium/high level of exposure to chromium (RR $1.80 ; 1.04-$ 3.12; $P$ trend 0.01 ), electromagnetic fields $(1.82 ; 1.18$ to 2.81 ; trend $P$
$0.02)$, and sedentary work $(1.32 ; 1.02$ 1.69; trend $P 0.05$ ); and with low level exposure to animal dust $(1.36 ; 1.10$ $1.69)$, cadmium $(1.47 ; 1.01-2.14)$, iron (1.93; 1.37-2.73), PAH $(1.47 ; 1.01-$ 2.14), and nickel (1.74; 1.23-2.44).

\section{Discussion}

Our study linked census data, a job exposure matrix, and cancer incidence data. The study was based on virtually complete assessment of cancer cases, and on reliable diagnoses,${ }^{14}$ and exact person-year calculation. The national job-exposure matrix used by us was semi-quanti- tative. FINJEM is insensitive to exposure variability within job titles but relatively specific in that exposure levels and exposure probabilities are supplied in particular time windows. The major drawback in the design was its ecological nature, the units being by necessity job titles rather than individuals. In consequence, exposures and cancer risk were not linked with individual women but averaged over each job title, which tended to drive risk estimates toward unity. All covariates were also assessed at the job title level. No exposure or covariate data 
TABLE 8

Gallbladder Cancer. Relative Risk for Low $\left(R R_{\llcorner}\right)$and Medium/High $\left(R_{H}\right)$ Levels of Exposure to FINJEM Agents, with $95 \%$ Confidence Intervals $(\mathrm{Cl})$

\begin{tabular}{|c|c|c|c|c|c|}
\hline Agent & $\mathbf{R R}_{\mathbf{L}}$ & $95 \% \mathrm{Cl}$ & $\mathbf{R R}_{\mathbf{H}}$ & $95 \% \mathrm{Cl}$ & $\mathrm{P}$ trend \\
\hline \multicolumn{6}{|l|}{ Physical agents } \\
\hline Heat & 0.88 & $0.71-1.08$ & - & - & 0.15 \\
\hline Ultraviolet radiation & 0.89 & $0.69-1.14$ & 0.88 & $0.55-1.38$ & 0.33 \\
\hline \multicolumn{6}{|l|}{ Chemical agents } \\
\hline Formaldehyde & 1.04 & $0.86-1.25$ & 0.74 & $0.46-1.19$ & 0.60 \\
\hline \multicolumn{6}{|l|}{ Organic solvents } \\
\hline Chlorinated hydrocarbons & 1.03 & $0.68-1.56$ & 0.84 & $0.56-1.25$ & 0.45 \\
\hline \multicolumn{6}{|l|}{ Organic dusts } \\
\hline Animal dust & 0.98 & $0.69-1.40$ & 1.13 & $0.36-3.53$ & 0.99 \\
\hline Flour dust & 1.00 & $0.84-1.20$ & 1.17 & $0.72-1.89$ & 0.74 \\
\hline Textile dust & 1.15 & $0.85-1.55$ & 1.07 & $0.81-1.41$ & 0.48 \\
\hline Wood dust & 1.08 & $0.89-1.30$ & 1.33 & $0.86-2.06$ & 0.18 \\
\hline Asbestos & 0.73 & $0.45-1.18$ & 1.07 & $0.57-2.02$ & 0.54 \\
\hline Man-made vitreous fibers & 0.88 & $0.60-1.31$ & 1.03 & $0.55-1.95$ & 0.76 \\
\hline Silica dust & 1.10 & $0.91-1.32$ & 0.89 & $0.50-1.59$ & 0.56 \\
\hline Other mineral dusts & 1.07 & $0.89-1.29$ & 0.57 & $0.14-2.29$ & 0.65 \\
\hline \multicolumn{6}{|l|}{ Metals } \\
\hline Cadmium & 1.15 & $0.64-2.09$ & 1.24 & $0.59-2.63$ & 0.46 \\
\hline Chromium & 0.91 & $0.61-1.36$ & 0.77 & $0.25-2.39$ & 0.53 \\
\hline Iron & 0.84 & $0.42-1.70$ & 0.91 & $0.13-6.48$ & 0.66 \\
\hline Lead & 0.85 & $0.58-1.24$ & 1.04 & $0.52-2.09$ & 0.60 \\
\hline Nickel & 0.89 & $0.50-1.58$ & 0.68 & $0.10-4.84$ & 0.59 \\
\hline Arsenic & 0.80 & $0.43-1.50$ & 1.09 & $0.54-2.20$ & 0.86 \\
\hline \multicolumn{6}{|l|}{ Engine exhaust } \\
\hline
\end{tabular}

- not estimated (small data).

Reference category: no exposure. Adjusted for turnover rate.

were gender-specific. In addition, turnover rate was not gender-specific. Job assessment was crosssectional within a year's span, which caused misclassification of exposure in jobs with high turnover; the latter was included in models but incompletely adjusted for because of reasons given above. We did not split any of the cancer sites to morphological subtypes (or anatomical subsites), because most of such subcategories would be too small for meaningful conclusions. The careful coding procedure should guarantee that there are very few metastatic tumors coded as primary cancers.
Having examined the associations between seven cancer sites and over 30 exposures there exists the very real possibility that some of the associations detected in our study are false positives related to the multiple comparison problems. This is a common problem in studies of this nature, and it is best to view many of the associations observed in this study as generating hypotheses that need to be confirmed by other studies.

Some of the associations observed in our hypothesis generating study have been reported in another investigation with stronger design, ie, in- cluding individual exposure assessment. ${ }^{1}$ High levels of physical activity are consistently associated with reduced risk of colon cancer. ${ }^{4}$ Initial associations between physical activity and colon cancer were derived from observations that people involved in active occupations were less likely to develop colon cancer. $^{15,16}$ Although physical activity was crudely categorized from occupational data in these studies, significant associations were detected and stimulated further examination of the associations, both for occupational and for other more comprehensive measures of total physical activity. 
TABLE 9

Pancreatic Cancer. Relative Risk for Low $\left(R R_{L}\right)$ and Medium/High $\left(R_{H}\right)$ Levels of Exposure to FINJEM Agents, with $95 \%$ Confidence Intervals (Cl)

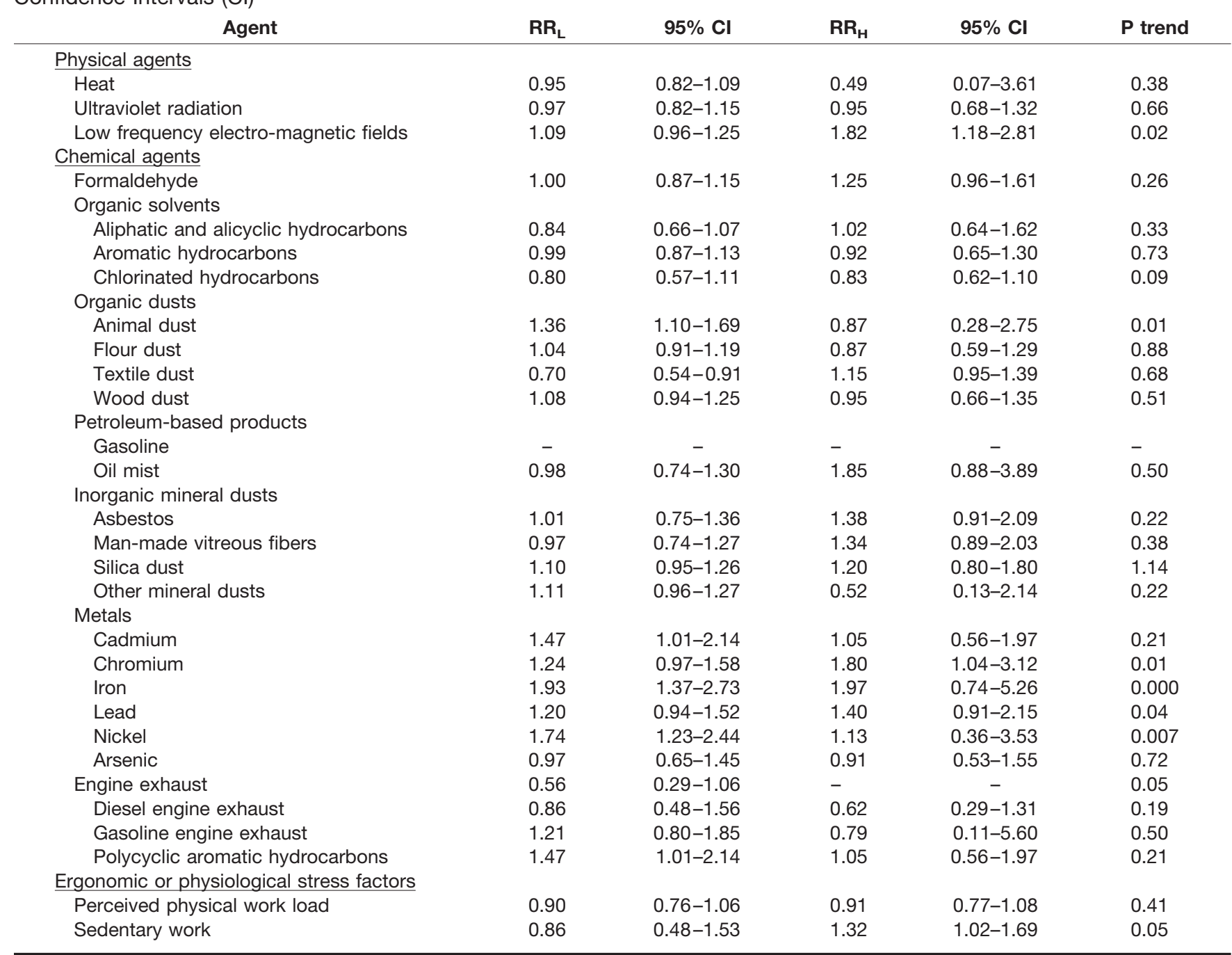

-not estimated (small data).

Reference category: no exposure. Adjusted for smoking and for turnover rate.

Several studies have replicated the inverse association between the job activity and colon or colorectal cancer. ${ }^{17-20}$

Adjustment for social class reduced confounding due to life styles associated with social class. In Finland, social class is a good proxy for most known life habits relevant in cancer causation. ${ }^{21,22}$

We also adjusted for tobacco smoking for cancer of the pancreas, and alcohol consumption for cancers of the liver and esophagus. Adjustment of both social class and smoking and drinking does not lead to over-adjustment, because social class among Finnish women is not directly correlated with those habits. However, the adjustment remained incomplete because of the aggregate (ecological) nature of the data, and because information on smoking and alcohol was not gender specific.

Our observation (though not significant) of an increased risk of cancer of the gallbladder associated with exposure to gasoline is a new finding. The findings of the Canadian case-control study ${ }^{1}$ on various organic fibers were not observed in this study for cancer of the gallbladder. Small numbers precluded strong conclusions pertaining to esophageal cancer. The elevations found in our study (asbestos, silica, and MMVF) were not reported in the Canadian study that instead, found elevated risks for chromium, combustion products, and toluene.

For stomach cancer, the excess observed for chlorinated hydrocarbon solvents, be it for low level only, is related with a finding of excess observed for female launderers, dry cleaners, and pressers in the United Kingdom. ${ }^{23}$ Our finding for electro- 
magnetic fields is novel, and needs confirmation. The putative mechanisms by which electromagnetic fields (EMF) may influence the cancer growth in the gastrointestinal tract are far from being convincing. In vitro exposures of cultured colon cancer cells to variable low-intensity, low-frequency electromagnetic fields have, however, been reported to result in increased cell growth, increased colony forming ability and increased expression of tumor associated antigens. ${ }^{24,25}$

The excesses of stomach cancer for silica, lead, gasoline, engine emissions, and coal combustion products observed in men in the $\mathrm{Ca}-$ nadian case-control study ${ }^{1}$ were not reproduced. Over $70 \%$ of the stomach cancers among women in Finland are adenocarcinomas, while all the other specific types represent less than $10 \%$ each. Thus, our results for stomach cancer are highly driven by adenocarcinomas of the stomach. There are certainly different nonoccupational etiological factors for these cancers, but the role of occupational ones for specific subtypes might well be similar.

Our observation of an excess pancreas cancer risk $\left(\mathrm{RR}_{\mathrm{H}} 1.8\right)$ associated with exposure to chromium compounds is in accordance with a recent meta-analysis, the latter showing a meta-risk ratio of $1.4(95 \%$ $\mathrm{CI}=0.9-2.3) .{ }^{6}$ When adjusted for nickel, the association of pancreas cancer with chromium became even stronger (SIR 1.75 (95\% CI $=1.17$ 2.60) for low level, and SIR 2.13 (95\% CI $=1.04-4.35)$ for medium/ high level, $P$ trend $=0.004)$. We found novel suggestions for increased risk associated with electromagnetic fields and sedentary work, while the excess associated with PAHs in the Canadian multisite casecontrol study ${ }^{1}$ was not reproduced.

For liver cancer former findings such as associations with chlorinated hydrocarbon solvents were not reproduced.

Our only finding for colon cancer concerned increased risk in seden- tary workers and decreased risk in physically loading occupations, in line with a previously confirmed association. ${ }^{4}$

Siemiatycki ${ }^{1}$ found a considerable number of occupational exposures that were associated with rectal cancer risk in men in Montreal, Canada. Our findings for chromium, oil mist, gasoline, and ionizing radiation were very different from those of the Canadian study.

The results of this study suggest that some occupational exposures may be associated with increased risk of gastrointestinal cancers. Because of inconsistencies between different studies and occasional shortage of power, focused studies with individual exposure estimates, such as the Canadian study, ${ }^{1}$ are needed to get answers for the remaining questions.

\section{Acknowledgment}

We thank Harri Paakkulainen for carrying out the Poisson regression analyses, and Antti Uutela for their help especially in the initial phases of the study. Leslie Stayner made useful comments on earlier versions of the manuscript.

\section{References}

1. Siemiatycki J. Risk Factors for Cancer in the Workplace. Boca Raton: CRC Press; 1991.

2. Cocco P, Ward MH, Buiatti E. Occupational risk factors for gastric cancer: an overview. Epidemiol Rev. 1996;18:218234.

3. Boffetta P, Kogevinas M, Simonato L, Wilbourn J, Saracci R. Current perspectives on occupational cancer risks. Int $J$ Occup Environ Health. 1995;1:315-325.

4. International Agency for Research on Cancer. IARC Handbooks of Cancer Prevention, Weight Control and Physical Activity, Vol 6. Lyon: IARC Press; 2002.

5. Weiderpass E, Partanen T, Kaaks R, et al. Occurrence, trends and environment etiology of pancreatic cancer. Scand J Work Environ Health. 1998;24:165-174.

6. Ojajärvi A, Partanen T, Ahlbom A, et al. Occupational exposures and pancreatic cancer: a meta-analysis. Occup Environ Med. 2000;57:316-324.

7. Ojajärvi A, Partanen T, Ahlbom A, et al. Risk of pancreatic cancer in workers exposed to chlorinated hydrocarbon solvents and related compounds: a meta- analysis. Am J Epidemiol. 2001;153:841850.

8. Partanen T, Kauppinen T, Boffetta P, Weiderpass E. Pancreas cancer. In: Savolainen H., ed. Encyclopaedia of Occupational Health and Safety. Geneva: International Labour Office. 1998;1:4.10-4.11.

9. Weiderpass E, Pukkala E, Kauppinen T, et al. Breast cancer and occupational exposures in women in Finland. Am $J$ Ind. Med. 1999;36:48-53.

10. Official Statistics of Finland. Central Statistical Office of Finland. Population Census 1970: Occupation and Social Position, Vol IX. Helsinki: Official statistics of Finland. 1974;VI C:104.

11. Kauppinen T, Toikkanen J, Pukkala E. From cross-tabulations to multipurpose exposure information systems: a new jobexposure matrix. Am J Ind Med. 1998;33: 409-417.

12. Breslow NE, Day NE, editors. Statistical methods in cancer research. Vol. II-The design and analysis of cohort studies. Lyon: IARC Scientific Publications 1987; No. 82:406 p.

13. Kolari R. Occupational Mobility 1970/ 1975. Official Statistics of Finland No. 97. Helsinki: Statistics Finland; 1983.

14. Teppo L, Pukkala E, Lehtonen M. Data quality and quality control of a population-based cancer registry. Experience in Finland. Acta Oncol. 1994;33:365-369.

15. Garabrant DH, Peters JM, Mack TM, Bernstein L. Job activity and colon cancer risk. Am J Epidemiol. 1984;119: 1005-1014.

16. Vena JE, Graham S, Zielezny M, Brasure J, Swanson MK. Occupational exercise and risk of cancer. Am J Clin Nutr. 1987;45:318-327.

17. Fraser G, Pearce N. Occupational physical activity and risk of cancer of the colon and rectum in New Zealand males. Cancer Causes Control. 1993;4:45-50.

18. Hsing AW, McLaughlin JK, Chow WH, et al. Risk factors for colorectal cancer in a prospective study among U.S. white men. Int J Cancer. 1998;77:549-553.

19. Levi F, Pasche C, Lucchini F, Tavani A, La Vecchia C. Occupational and leisuretime physical activity and the risk of colorectal cancer. Eur J Cancer Prev. 1999;8:487-493.

20. Tavani A, Braga C, La Vecchia C, et al. Physical activity and risk of cancers of the colon and rectum: an Italian casecontrol study. Br J Cancer. 1999;79: 1912-1916.

21. National Public Health Institute, Finland. Health Behaviour among Finnish Adults' Survey 1978-1991. 1991.

22. Pukkala E. Cancer risk by social class 
and occupation. A survey of 109,000 cancer cases among Finns of working age. Contributions to Epidemiology and Biostatistics, Vol 7. Basel: Karger; 1995: 277.

23. Simpson J, Roman E, Law G, Pannett B. Women's occupation and cancer: prelim- inary analysis of cancer registrations in England and Wales, 1971-1990. Am J Ind Med. 1999;36:172-185.

24. Ruiz Gomez MJ, Pastor Vega JM, de la Pena L, Gil Carmona L, Martinez Morillo M. Growth modification of human adenomcarcinoma cells exposed to a low- frequency electromagnetic field. J Physiol Biochem. 1999;552:79-83.

25. Phillips JL, Winters WD, Rutledge L. In vitro exposure to electromagnetic fields: changes in tumour cell properties. Int $J$ Radiat Biol Relat Stud Phys Chem Med. 1986;493:463-469. 